\title{
Relación entre la Composición y la Actividad Antitríptica de Sueros de Soja y Tofu y Comportamiento Térmico de sus Proteínas Aisladas
}

\author{
Pablo. A. Sobral ${ }^{1}$ y Jorge. R. Wagner ${ }^{2}$ \\ (1) Centro de Investigación y Desarrollo en Criotecnología de Alimentos (CIDCA), Facultad de \\ Ciencias Exactas (UNLP-CONICET), 47 y 116 (B1900AJJ) La Plata, Buenos Aires-Argentina \\ (2) Universidad Nacional de Quilmes, Departamento de Ciencia y Tecnología, Roque Sáenz Peña \\ 352 (B1876BXD) Bernal, Buenos Aires-Argentina (e-mail: jwagner@unq.edu.ar)
}

\begin{abstract}
Resumen
Se analizaron las diferencias en composición y actividad antitríptica de sueros de soja y suero de tofu en relación al comportamiento térmico de sus proteínas. El suero de soja fue obtenido a partir de harina de soja desgrasada y el suero de tofu es el residuo líquido industrial de la fabricación del tofu. Ambos sueros contienen carbohidratos como componentes mayoritarios, proteínas, nitrógeno no proteico y sales. El suero de tofu presentó valores de densidad, extracto seco y proteínas más bajos, y una actividad antitríptica tres veces inferior que el suero de soja. Ensayos por calorimetría diferencial de barrido de proteínas aisladas del suero de soja mostraron las endotermas de la lectina y los factores antitrípticos de Kunitz y Bowman-Birk, mientras que las de suero de tofu sólo muestran este último factor. Las diferencias entre sueros pueden explicarse por los diferentes procesos de obtención.
\end{abstract}

\section{Relationship between the Composition and Antitryptic Activity of Soy and Tofu Wheys and Thermal Behavior of their Isolated Protein}

\begin{abstract}
The differences in composition and antitryptic activity of soy whey and tofu whey, in relation to thermal behavior of its proteins, were studied. Soy whey was obtained from an aqueous extract of defatted soybean flour and tofu whey is a liquid industrial residue from the tofu production. Both byproducts contain carbohydrates as main components, proteins, non-protein nitrogen and salts. Tofu whey presented lower values of density, dry extract and proteins, while the antitryptic activity was three times lower than in soy whey. Differential scanning calorimetric studies of soy whey proteins showed the endotherms of lectin and antitryptic factors of Kunitz and Bowman-Birk, while the thermogram corresponding to tofu whey proteins showed only the last factor. The differences between wheys can be explained by the differences in the manufacturing processes.
\end{abstract}

Key words: soybean whey, tofu whey, proteins, antitryptic activity, thermal behavior 


\section{INTRODUCCIÓN}

El aprovechamiento de la soja, involucra una serie de procesos destinados a obtener los componentes de interés (aceites, concentrados, aislados proteicos, etc.) y eliminar o inactivar los componentes indeseables (factores antinutricionales) y fibra. Tanto la metodología usada tradicionalmente para la obtención de aislados proteicos como el proceso de producción de tofu generan importantes volúmenes de líquidos residuales que representan un problema para el medio ambiente. La producción tradicional de aislados consiste en una extracción cercana al 90\% del material nitrogenado de la harina de soja en condiciones alcalinas ( $\mathrm{pH} \mathrm{8-9} \mathrm{con} \mathrm{un} \mathrm{bajo} \mathrm{porcentaje} \mathrm{de}$ desnaturalización (Pearson, 1983). La separación de componentes insolubles (fibra) produce un extracto que contiene las proteínas de soja, $75 \%$ de las cuales son globulinas de reserva y el $25 \%$ restante son proteínas biológicamente activas (Cheftel et al., 1989), conocidas como proteínas de suero de soja (Sorgentini y Wagner, 1999). La acidificación de este extracto hasta el pH isoeléctrico $(4,5)$ permite la precipitación de las globulinas de reserva (7S y 11S) dejando un suero de soja (SS).

La producción de tofu comienza con la preparación de la leche de soja a partir de porotos frescos; son muy variados los procedimientos conocidos pero la mayoría de ellos comienzan con una etapa de remojado del poroto (8-10 hs), seguido de una molienda-extracción a $80-90^{\circ} \mathrm{C}$ en exceso de agua (inactivación de lipoxigenasa), una cocción destinada a la eliminación de volátiles e inactivación de los factores antitrípticos y hemaglutinina o lectina (Liu, 1999; Valentas et al., 1991). La filtración o el prensado remueve las fibras y proteínas insolubles (okara) de la dispersión-emulsión proteína-aceite $(\mathrm{pH} \approx 6,5 ; 9 \%$ sólidos) la cual se conoce como leche de soja. La coagulación de las proteínas de reserva de esta leche mediante el agregado de sales de calcio y magnesio $(2-4 \%$ del peso original, 10-30 min, entre 70 y $85^{\circ} \mathrm{C}$ ) forma una estructura tipo gel, el tofu, el cual expulsa el suero de tofu (ST).

Los sueros de soja contienen los hidratos de carbono solubles del grano de soja (mono-, di- y oligosacáridos); siendo los mayoritarios en el suero de tofu, el disacárido sacarosa y los oligosacáridos estaquiosa y rafinosa (Espinosa-Martos et al., 2006; Espinosa-Martos y Rúperez, 2006). La fracción proteica del suero de soja está constituida mayoritariamente por la lectina (L) y los factores antitrípticos de Kunitz y Bowman-Birk y enzimas como la $\beta$-amilasa, lipooxigenasa y ureasa (Sorgentini y Wagner, 1999). El inhibidor de tripsina de Kunitz (KTI) tiene una masa molecular de 20 kDa y su actividad no se modifica en el rango de $\mathrm{pH}$ 1-14 y es térmicamente estable en condiciones de baja humedad (Koshiyama et al., 1981; Lin y $\mathrm{Ng}, 2008$ ). Estos últimos autores informaron propiedades benéficas del KTI que incluyen el incremento en la producción de óxido nítrico por los macrófagos, así como una disminución en la proliferaciones de células cancerosas de mama e hígado. El inhibidor de Bowman-Birk (BBTI) que resiste las temperaturas de cocción y pH del estómago humano debido al alto número de puentes disulfuro en su estructura (Birk, 1987), posee propiedades anticancerígenas (Kennedy, 1993) y estimulantes del sistema inmune (Harms-Ringdahl et al., 1979).

Otras sustancias solubles minoritarias de la soja, como son las isoflavonas y las sales, se encuentran también en los sueros de soja. En el suero de tofu se encuentran niveles importantes de las isoflavonas Genistin y Daidzin, fitoestrógenos de reconocidos efectos beneficiosos para la salud (Espinosa-Martos et al., 2006). La presencia de sales en el suero de tofu fue evaluada mediante la determinación de cenizas (Espinosa-Martos el al., 2006; Ben Ounis et al., 2008), siendo los minerales predominantes las sales de calcio y/o magnesio adicionadas para la coagulación proteica (Liu, 1999). En el suero proveniente de la obtención de aislados de soja la sal predominante es cloruro de sodio formado en las etapas de acidificación y neutralización (Sorgentini y Wagner, 1999).

Los procesos industriales generan grandes cantidades de estos sueros que debido a su carga orgánica representan un problema ambiental para su descarte en forma directa. Han sido poco estudiados como producto integral, aun cuando son potencialmente valiosos debido al contenido de oligosacáridos, isoflavonas, vitaminas, oligoelementos, péptidos y proteínas biológicamente activas que una vez inactivadas poseen un alto valor biológico.

El objetivo del trabajo fue analizar comparativamente la composición de ambos sueros, determinar la actividad antitríptica residual y el comportamiento térmico de sus proteínas aisladas, y evaluar los resultados en relación a las materias primas y los procesos que conducen a su obtención. 


\section{MATERIALES Y MÉTODOS}

El suero de soja (SS) fue obtenido según el procedimiento descrito por Sorgentini y Wagner (1999). Extracción acuosa de harina de soja desgrasada, libre de solvente, no tratada térmicamente (Santista S.A., Brasil) con una relación agua: harina de 10:1 (2 hs, temperatura ambiente) y ajuste periódico del $\mathrm{pH}$ a $8,0(\mathrm{NaOH} 2 \mathrm{~N})$. Centrifugación de la mezcla a $10500 \mathrm{~g}$ por 15 min a $20^{\circ} \mathrm{C}$ (Beckman Coulter Avanti J-25, rotor JA-14) para eliminar la fracción insoluble. El extracto obtenido se llevó a pH $4,5(\mathrm{HCl} 2 \mathrm{~N})$, se dejó 2 hs a $4^{\circ} \mathrm{C}$ y se centrifugó a $10500 \mathrm{~g}$ por $20 \mathrm{~min}$ a $20^{\circ} \mathrm{C}$ para separar las globulinas de reserva (GR) del suero de soja (SS). El suero de tofu (ST) fue cedido por una industria local (Soyana S.H.). Ambos sueros fueron liofilizados (equipo HETO FD4) obteniendo las muestras de SSL y STL.

Sobre los sueros se determinó el contenido total de carbohidratos empleando el método del fenol sulfúrico (Dubois et al., 1956) y el contenido total de material nitrogenado (proteína bruta) por

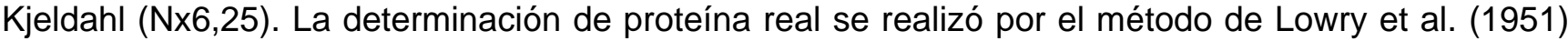
sobre los precipitados (sin azúcares libres) obtenidos con TCA al 12\% p/v y lavados al menos 5 veces con solución TCA para reducir la interferencia de azúcares reductores. Para los sueros liofilizados la precipitación se realizó sobre muestras solubilizadas (relación agua: liofilizado, 10:1). La eliminación de azúcares libres se realizó lavando 5 veces el precipitado con solución acuosa al 12\% de TCA, empleando en cada lavado la mitad del volumen inicial y centrifugando (10000 rpm, $15 \mathrm{~min}$, $20^{\circ} \mathrm{C}$ ) descartando el sobrenadante. El grado de glicosilación se estimó a partir de la cantidad de proteínas y glúcidos en estos precipitados. El porcentaje de extracto seco de los sueros líquidos se determinó secando en estufa $\left(105^{\circ} \mathrm{C}\right.$; hasta peso constante) el suero previamente liofilizado. El contenido de minerales se determinó como cenizas por calcinación a $550^{\circ} \mathrm{C}$ hasta cenizas blancas. La contenido de lípidos se determinó sobre suero liofilizado por extracción con mezcla de Folch (cloroformo: metanol 2: 1), centrifugación, evaporación del solvente y pesada del residuo graso.

La actividad antitríptica se determinó según el método de González y Carrillo (1987), con leves modificaciones. En este ensayo se midió la disminución de la actividad de la tripsina sobre hemoglobina desnaturalizada, debido a la adición del suero de soja. La proteólisis se detiene por adición de ácido tricloroacético (TCA) y en el sobrenadante se determinan por Folin $\left(\mathrm{A}_{650}\right)$ los péptidos solubles y los aminoácidos liberados por la proteólisis. Se realizó un ensayo control (100\% actividad proteolítica) en ausencia de inhibidores y un ensayo en blanco ( $0 \%$ actividad) con adición de TCA a t=0. El \% inhibición de la tripsina se calculó según las siguientes expresiones:

$$
\begin{aligned}
& \mathrm{A}_{\text {control }}-\mathrm{A}_{\text {blanco }}=100 \% \text { actividad } \\
& \mathrm{A}_{\text {muestra }}-\mathrm{A}_{\text {blanco }}=\mathrm{X} \% \text { actividad } \\
& 100-\mathrm{X}=\% \text { inhibición }
\end{aligned}
$$

El aislamiento de las proteínas a partir de los sueros líquidos se realizó mediante precipitación con acetona (p.a. ACS Baker) a $0^{\circ} \mathrm{C}$, en una relación acetona: suero 1: $1 \mathrm{v} / \mathrm{v}$, agregando el solvente en forma progresiva (10-15 min) sobre el suero en condiciones de agitación suave. Las proteínas fueron separadas por centrifugación $\left(10500 \mathrm{~g}, 4^{\circ} \mathrm{C}, 20 \mathrm{~min}\right.$.) y secadas por liofilización para obtener las proteínas de suero de soja (PSS) y las proteínas de suero de tofu (PST). Se determinó la cantidad de proteína liofilizada recuperada a partir de ambos sueros y el contenido de material nitrogenado en estas proteínas aisladas utilizando el método de Kjeldahl.

El comportamiento térmico de las proteínas aisladas en solución acuosa (relación muestra:agua destilada, 3:7 p/p) fue analizado mediante calorimetría diferencial de barrido (DSC) en cápsulas comerciales de aluminio selladas herméticamente. Se utilizó un equipo T.A. Instruments, modelo Q100, analizando los datos mediante el software del equipo (T.A. Universal Analysis 2000 for Windows 2000/XP).

En las proteínas aisladas se estimó el contenido de minerales por distintos métodos. Se determinó la conductividad de soluciones $0,5 \mathrm{~g} / \mathrm{l}$ de las proteínas liofilizadas en agua bidestilada (conductividad = $0,89 \pm 0,12 \mu \mathrm{S} / \mathrm{cm}$ ) empleando agitación magnética. Las medidas se realizaron a $25^{\circ} \mathrm{C}$ con un 
conductímetro YSI modelo 35 y una celda conductimétrica YSI 3401; la constante de la celda utilizada $(1,084 \pm 0,067 / \mathrm{cm})$ fue determinada a partir de una solución patrón de $\mathrm{KCl} 0,01 \mathrm{~N}$. Las cenizas se determinaron por calcinación a $550^{\circ} \mathrm{C}$ hasta cenizas blancas. El porcentaje de cenizas fue calculado como $100 \times\left(m_{c} / m_{P L}\right)$, donde $m_{c}$ son los $g$ de cenizas provenientes de $m_{P L} g$ de muestra. Dichas cenizas fueron disueltas en ácido nítrico 0,14N y Lantano 0,5\%, llevadas hasta un volumen apropiado en matraz y filtradas por membrana de $0,45 \mu \mathrm{m}$ de tamaño de poro. Sobre las soluciones resultantes se determinó el contenido de calcio y magnesio mediante espectroscopía de absorción atómica utilizando un espectrofotómetro Shimadzu AA-6650. El porcentaje de calcio o magnesio fue calculado como $m_{m} \times\left(m_{c} / 100\right)$ donde $m_{m}$ son los $g$ de metal determinado por espectroscopia atómica en $100 \mathrm{~g}$ de cenizas y $\mathrm{m}_{\mathrm{c}}$ son los $\mathrm{g}$ de cenizas en $100 \mathrm{~g}$ de muestra.

Todas las determinaciones fueron realizadas al menos por triplicado y los valores medios expresados con su desviación estándar.

Los resultados obtenidos se analizaron mediante análisis de la varianza (ANOVA) y las diferencias entre medias mediante el Test de Fisher a un nivel de significación $\alpha=0,05$. (Statgraphics Plus versión 2.1, Statistical Graphics Corp., Princeton, USA).

\section{RESULTADOS Y DISCUSIÓN}

Los sueros provenientes de la elaboración de aislado de soja (SS) y de tofu (ST), son residuales líquidos que si bien provienen del grano de soja como materia prima, incluyen distintos procesos en su obtención. Es esperable por lo tanto que el tipo de sustancias presentes (proteínas e hidratos de carbono fundamentalmente) en ambos sueros sean las mismas, no así su contenido relativo. Por tratarse de subproductos que fueron expuestos a distintos tratamientos y condiciones del medio $(\mathrm{pH}$, concentración salina, tipo de sales, temperatura), es lógico pensar que las proteínas exhiban distintos grados de inactivación o desnaturalización. Por este motivo, se encaró el estudio de la composición y la actividad antitríptica de los sueros en relación al comportamiento térmico de sus proteínas aisladas. Esta información es importante debido a que la potencial utilización de cualquiera de estos sueros como fuente de nutrientes o como alimento funcional (por las propiedades de proteínas, oligosacáridos e isoflavonas), requiere de la ausencia de antiproteasas activas o de su inactivación a niveles inocuos.

\section{Composición}

La Tabla 1 muestra el resultado del análisis de la composición de los sueros. Se puede observar que en ambos subproductos los carbohidratos resultan ser el componente mayoritario seguido de las proteínas. En el suero de soja liofilizado (SSL), no fue posible detectar lípidos, mientras que en el suero de tofu liofilizado (STL) la cantidad detectada de lípidos residuales fue muy baja, 1,00 \% p/p. Las composiciones de ambos sueros están relacionadas a las de las materias primas y a los procesos de los cuales provienen. La ausencia de lípidos en el suero proveniente de la producción de aislados se debe básicamente al bajo contenido de la harina de partida (54\% proteínas, 38\% carbohidratos, $1 \%$ aceite y $6 \%$ cenizas). Teniendo en cuenta que la composición típica de una leche de soja en base seca es de $42 \%$ proteínas, $28 \%$ lípidos y $26,9 \%$ (USDA, 2004), y que a partir de ella se prepara el tofu y resulta como efluente el suero de tofu, se puede inferir que la mayor parte de los lípidos pasa a formar parte del tofu y no del suero. Durante la preparación del tofu se produce la coagulación de las proteínas de reserva (7S y 11S) de la leche de soja, junto con la mayoría de los lípidos, quedando el suero enriquecido en oligosacáridos y proteínas solubles.

EI SS presentó un contenido de proteínas y carbohidratos significativamente mayor que el observado en ST $(\alpha=0,05)$; siendo proporcionalmente mayor el contenido de hidratos de carbono. Por este motivo la relación entre proteína bruta y glúcidos fue también significativamente diferente para los dos sueros, dando valores de 1: 3,03 y 1: 3,10 para SS y SSL y de 1: 2,42 y 1: 2,50 para ST y STL, respectivamente. Recientemente, Espinosa-Martos et al. (2006) informaron para un suero de tofu, un contenido similar de carbohidratos totales $(8,8 \mathrm{~g} / \mathrm{l}$, incluye $0,6 \mathrm{~g} / \mathrm{l}$ de fibra soluble) pero muy superior de proteínas $(5,3 \mathrm{~g} / \mathrm{l})$, lo que da por lo tanto una relación proteína bruta: carbohidratos $(1: 1,66)$ diferente a la determinada para ST. 
Tabla 1: Composición química de ambos tipos de suero en estado líquido y deshidratado. El NNP (nitrógeno no proteico) se calculó como la diferencia entre proteína bruta y la real. ND: no determinado.

\begin{tabular}{|c|c|c|c|c|c|}
\hline \multirow{2}{*}{ Componente } & \multicolumn{2}{|c|}{ Suero de soja } & \multicolumn{2}{c|}{ Suero de tofu } \\
\cline { 3 - 6 } \multicolumn{2}{|c|}{} & $\begin{array}{c}\text { Líquido } \\
(\mathrm{g} / \mathrm{l})\end{array}$ & $\begin{array}{c}\text { Deshidratado } \\
(\% \mathrm{p} / \mathrm{p})\end{array}$ & $\begin{array}{c}\text { Líquido } \\
(\mathrm{g} / \mathrm{l})\end{array}$ & $\begin{array}{c}\text { Deshidratado } \\
(\% \mathrm{p} / \mathrm{p})\end{array}$ \\
\hline \multirow{2}{*}{ Proteína } & Bruta (NTx6,25) & $5,28 \pm 0,06$ & $17,60 \pm 0,03$ & $3,62 \pm 0,12$ & $15,31 \pm 0,18$ \\
\cline { 2 - 6 } & Real & $4,69 \pm 0,47$ & $10,73 \pm 0,09$ & $2,23 \pm 0,16$ & $10,27 \pm 0,75$ \\
\hline NNP & 0,59 & 6,87 & 1,39 & 5,04 \\
\hline Carbohidratos & $16,01 \pm 0,88$ & $54,57 \pm 2,86$ & $8,77 \pm 0,38$ & $38,22 \pm 1,16$ \\
\hline Lípidos & $\mathrm{ND}$ & $\approx 0$ & $\mathrm{ND}$ & $0,99 \pm 0,01$ \\
\hline \multicolumn{2}{|c|}{ Extracto seco } & $32,77 \pm 1,82$ & 100 & $27,35 \pm 0,31$ & 100 \\
\hline Cenizas & $4,39 \pm 0,03$ & $13,40 \pm 0,30$ & $5,14 \pm 0,01$ & $16,67 \pm 0,03$ \\
\hline Densidad $\left(25^{\circ} \mathrm{C}\right)$ & $1020 \pm 5$ & $\mathrm{ND}$ & $1012 \pm 3$ & $\mathrm{ND}$ \\
\hline
\end{tabular}

El menor contenido proteico hallado en el suero de tofu industrial estudiado en este trabajo puede atribuirse tanto a una precipitación más eficiente de las globulinas de almacenamiento por agregado de sales de calcio, como a una mayor retención de proteínas de suero durante la formación de la red

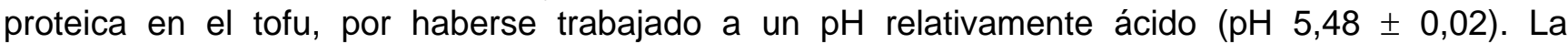
comparación entre las muestras SS y ST en la Tabla 1 reveló que el suero de tofu era más diluido; contiene el $55 \%$ de los glúcidos y el 69 \% de proteína bruta hallada en SS. Esto se traduce en valores inferiores de extracto seco y densidad para el ST. El bajo contenido de sólidos totales en ambos sueros (extracto seco $<3,3 \%$ ) justifica su deshidratación para obtener muestras de menor volumen, más estables y fáciles de almacenar.

Como es de esperar, un análisis comparativo entre los sueros líquidos y deshidratados reveló una composición equivalente si se expresa en peso seco. La liofilización reduce las diferencias vistas entre los sueros de soja y de tofu en estado líquido; el STL contiene el $96 \%$ de la proteína real, el $87 \%$ de la proteína bruta y el $70 \%$ de los glúcidos hallados en SSL. El contenido de cenizas (\% p/p) fue de $13,40 \pm 0,30$ y 16,67 $\pm 0,03$ para SSL y STL, respectivamente; el contenido mayor de minerales en STL se atribuiría a las sales de calcio y/o magnesio agregadas durante la elaboración del tofu. $\mathrm{El} \mathrm{CaSO}_{4}$ produce un tofu rico en calcio de consistencia suave-intermedia; el agregado de $\mathrm{MgCl}_{2}$ (nigari) y $\mathrm{CaCl}_{2}$ incrementa la consistencia y el sabor dulce.

Un resultado interesante de señalar es que las proteínas precipitadas y lavadas con TCA para la determinación de proteína real (como fue explicado en Materiales y Métodos), al ser analizadas por el método de Dubois, mostraron contener carbohidratos, los cuales dan una idea del grado de glicosilación. El contenido de glúcidos unidos a las proteínas de ambos sueros fue del orden de 5$7 \%$, expresados en \% p/p sobre peso seco de precipitado. En el caso particular de las proteínas de suero de tofu, se pudo observar que si la precipitación se realizaba sobre el suero líquido, el grado de glicosilación era un 30\% inferior al observado sobre las proteínas del suero liofilizado. Estos resultados sugieren un cierto efecto de las etapas incluidas en la liofilización (principalmente el efecto de la crioconcentración de componentes por formación de hielo durante la congelación) sobre el grado de glicosilación de las proteínas del suero. Sin embargo, son sólo resultados preliminares, requiriendo estudios más específicos y confirmatorios.

\section{Actividad antitríptica}

El porcentaje de inactivación de la tripsina en las condiciones del ensayo descriptas en Materiales y Métodos, fue del $51,6 \pm 4,58$ y $16,7 \pm 0,36$ para SSL y STL, respectivamente. En otras palabras, la actividad antitríptica en el suero industrial de tofu es 3 veces menor que en el suero obtenido en nuestro laboratorio como residual de la obtención de aislados. La obtención de aislados proteicos de soja se realiza a partir de harinas que deben tener una elevada solubilidad proteica para obtener extractos de alto rendimiento en proteínas. Para lograr esto se emplean harinas desgrasadas con hexano, en las cuales este solvente es eliminado con una desnaturalización mínima, para evitar la 
insolubilización. Estas harinas son activas, es decir, contienen los factores antitrípticos sin inactivar, los cuales se conservan activos hasta después de la precipitación isoeléctrica. Debido a su alta solubilidad en ese medio quedan mayoritariamente en el suero, que resulta por lo tanto con una alta actividad antitríptica. En STL, la disminución en la actividad antitríptica se corresponde con el proceso de obtención del tofu el cual incluye al menos tres tratamientos térmicos importantes, la inactivación de la lipoxigenasa, la cocción destinada para la inactivación y eliminación de volátiles y, finalmente, la coagulación final a una temperatura óptima entre 75 y $80^{\circ} \mathrm{C}$. El suero de tofu presenta igualmente una actividad antitríptica residual que se puede anticipar que es debida a la presencia del factor de Bowman-Birk, como será confirmado seguidamente en estudios por calorimetría diferencial de barrido.

\section{Comportamiento térmico de proteínas aisladas}

En la tabla 1 se mostró que el ST tiene un menor contenido proteico que el SS; expresando los datos en forma relativa resulta que el ST contiene el 68.6 y el $47.5 \%$ de las proteínas bruta y real halladas en SS, respectivamente. Por precipitación de proteínas con acetona, la cantidad de muestra liofilizada obtenida a partir de los sueros fue de 2,20 $\pm 0,05$ y 3,86 $\pm 0,08$ g/l para SS y ST, respectivamente. El material nitrogenado (Kjeldahl; Nx6,25) hallado en estas muestras fue $54,25 \pm$ $2,13 \%$ p/p para las provenientes de suero de soja y 40,54 $\pm 1,17 \%$ p/p para las de suero de tofu. De esto resulta que, a partir de un suero con menor contenido proteico como es el suero de tofu industrial, se obtiene una mayor masa de muestra proteica, pero que tiene un contenido menor de material nitrogenado. Estos hallazgos sugieren una mayor co-precipitación de otros componentes, fundamentalmente minerales y glúcidos, junto a las proteínas provenientes del suero industrial.

En la figura 1 se presenta el análisis del comportamiento térmico de las muestras proteicas realizado por calorimetría diferencial de barrido (DSC). El termograma superior corresponde al análisis térmico de una dispersión acuosa de proteínas de suero de soja (PSS, 30\% p/p) y los resultados son equivalentes a los de un trabajo previo (Sobral y Wagner, 2007). El termograma presenta dos transiciones con temperaturas de pico (Tp) de $74,37 \pm 0,35^{\circ} \mathrm{C}$ y $88,52 \pm 0,02^{\circ} \mathrm{C}$, que según trabajos previos (Sorgentini y Wagner, 1999) corresponden a la desnaturalización del factor antitríptico de Kunitz (KTI) y la lectina (L), respectivamente, con un valor de entalpía total de desnaturalización $\left(\Delta \mathrm{H}_{\text {total }}\right)$ de $6,98 \pm 0,33 \mathrm{~J} / \mathrm{g}$ materia seca. El análisis de esta misma muestra pero a mayor concentración (dispersión acuosa al 50\% p/p), debido a ser una condición con menor agua disponible, produjo un ligero incremento en la entalpía de desnaturalización $\left(\Delta \mathrm{H}_{\text {total }}=7,12 \pm 0,52 \mathrm{~J} / \mathrm{g}\right)$ y en las temperaturas de transición (Tp de $76,20 \pm 1,92^{\circ} \mathrm{C}$ y $89,28 \pm 0,76^{\circ} \mathrm{C}$, para $\mathrm{KTI}$ y $\mathrm{L}$, respectivamente). Adicionalmente, el incremento de muestra dentro de la cápsula permitió la detección de un pequeño pico a $126,9^{\circ} \mathrm{C}(\Delta \mathrm{H}=1,25 \mathrm{~J} / \mathrm{g})$ que corresponde al factor antitríptico de Bowman-Birk (BBTI), si se tiene en cuenta su alta estabilidad térmica. Este resultado fue confirmado por medio de un ensayo con una muestra patrón de BBTI, con el cual se registró una transición a $128,76^{\circ} \mathrm{C}$, con un $\Delta \mathrm{H}$ de $9,17 \mathrm{~J} / \mathrm{g}$. La materia prima de partida (harina de soja no tratada térmicamente) y la ausencia de tratamientos desnaturalizantes durante la obtención del SS, justifica el termograma DSC de PSS, cuyas tres endotermas indican la presencia de $\mathrm{L}$ y ambos factores antitrípticos (KTI y $\mathrm{BBTI})$ con un alto grado de la estructura nativa conservada. Evidentemente, tampoco resultaron procesos desnaturalizantes, tanto la liofilización del suero líquido como la posterior precipitación con acetona.

Por otra parte, en la misma figura se observa que el termograma de las proteínas aisladas a partir de suero de tofu (PST), no presenta los picos correspondientes a $\mathrm{KTI}$ y $\mathrm{L}$, aunque se detecta una pequeña inflexión a $87,2^{\circ} \mathrm{C}$ y una transición a $138,52 \pm 2,46^{\circ} \mathrm{C}(\Delta \mathrm{H}=6,12 \pm 0,48 \mathrm{~J} / \mathrm{g})$. Estos resultados se atribuyen a los numerosos tratamientos térmicos, mencionados previamente, a los que son sometidas estas proteínas durante la producción del tofu, que provocan la desnaturalización total de $\mathrm{KTI}$, casi total de $\mathrm{L}$ y dejan activo al factor BBTI (transición a $138,5^{\circ} \mathrm{C}$ ). Los resultados obtenidos por DSC para las proteínas de ambos sueros (PST y PSS) guardan correlación con las medidas de actividad antitríptica en los mismos. Por un lado, la presencia de KTI activo en PSS es la razón por la cual el suero de soja tiene una actividad antitríptica 3 veces superior al suero de tofu; por otro lado, con la presencia de BBTI activo en PST se explica la actividad antitríptica residual en el suero de tofu. 


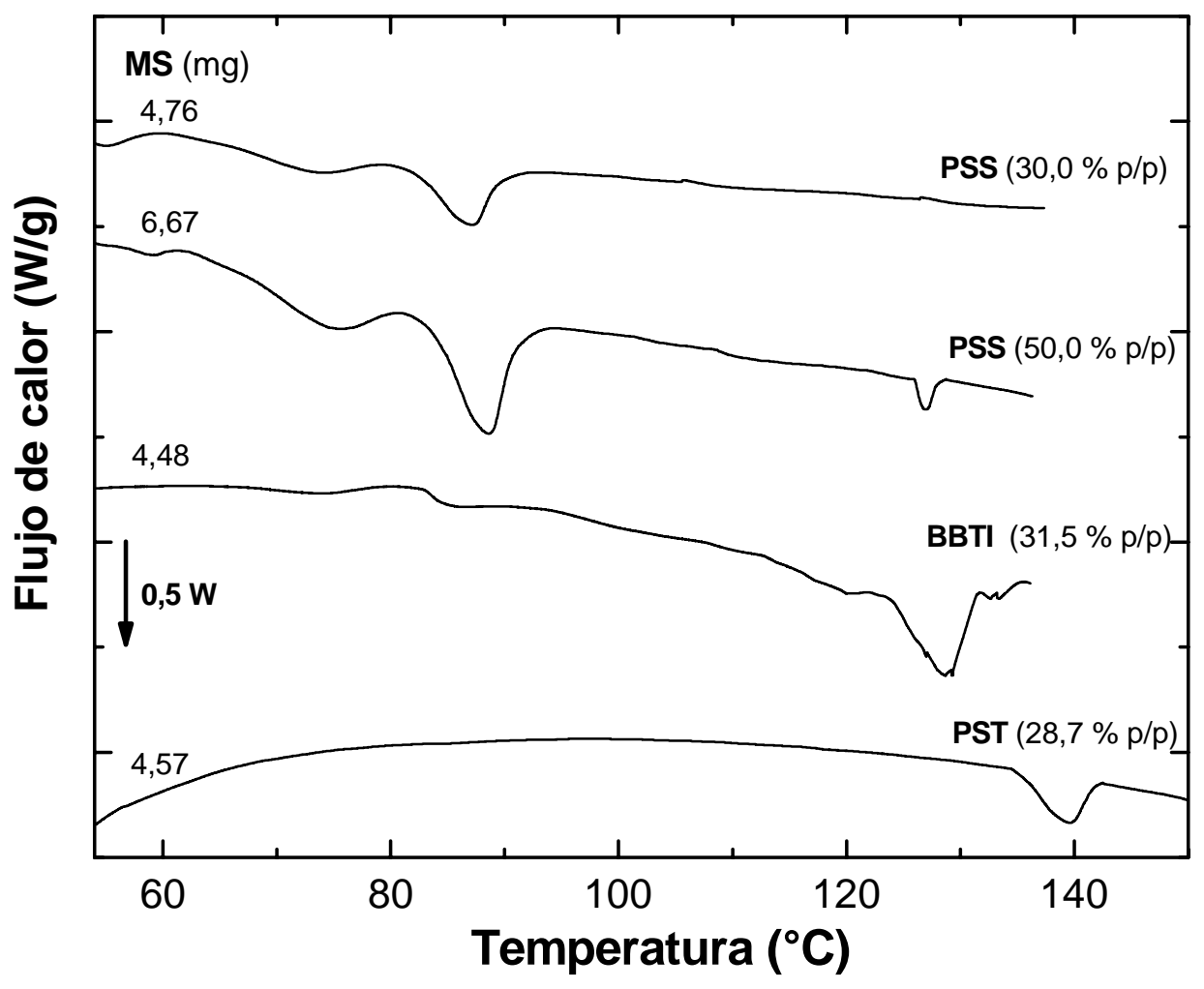

Fig. 1: Termogramas de dispersiones acuosas de proteínas aisladas de suero de soja y tofu. PSS: Proteínas de suero de soja, PST: Proteínas de suero de tofu, BBTI: factor antitríptico de Bowman-Birk (Sigma). MS: masa seca.

El incremento en la Tp de la endoterma correspondiente a BBTI en la muestra PST, respecto a la hallada en PST y en el patrón, puede atribuirse a la presencia de sales. En el proceso industrial de obtención del tofu se adicionan sales de calcio y/o magnesio que precipitan junto con las proteínas 75 y 11S, pero un remanente de esas sales queda en el suero de tofu. En el proceso de insolubilización con acetona, las proteínas del suero de tofu pueden coprecipitar junto con las sales de cationes divalentes presentes, provocando una estabilización adicional del factor BBTI. Trabajos previos hacen referencia al efecto que tiene el calcio de incrementar la temperatura de desnaturalización de las globulinas de soja (Scilingo y Añon, 1996); un efecto similar podría ser esperable para el BBTI.

Para corroborar si el comportamiento térmico anómalo de BBTI en suero de tofu es debido a efecto salino, se realizaron determinaciones de cenizas, $\mathrm{Ca}$ y $\mathrm{Mg}$ de las muestras de PSS y PST, y de la conductividad de soluciones de dichas muestras en agua bidestilada (Tabla 2). Puede observarse que efectivamente tanto el contenido de cenizas como de calcio son superiores en la muestra proteica que proviene del suero de tofu (PST); el contenido de Ca en esta muestra es 7 veces superior al de PSS. Por las medidas de conductividad, que son equivalentes en ambas muestras, es fácil deducir que las sales que contribuyen a la medida son las que no están unidas a las proteínas de suero, y por ende el catión Ca estaría ligado.

Tabla 2. Contenido de minerales en las muestras proteicas aisladas de suero de soja (PPS) y de suero de tofu (PST).

\begin{tabular}{|c|c|c|c|c|}
\hline Muestra & Cenizas (\% p/p) & Conductividad $(\mu \mathrm{S} / \mathrm{cm})$ & $\mathrm{Ca}(\% \mathrm{p} / \mathrm{p})$ & $\mathrm{Mg}(\% \mathrm{p} / \mathrm{p})$ \\
\hline PSS & $11,23 \pm 0,81$ & $96,15 \pm 3,56$ & 1,09 & 0,73 \\
\hline PST & $16,29 \pm 0,92$ & $95,61 \pm 5,41$ & 6,96 & 0,36 \\
\hline
\end{tabular}




\section{CONCLUSIONES}

Ambos sueros, debido a su composición y volúmenes generados representan un problema ambiental, de modo que debe pensarse en el aprovechamiento del mismo tal cual o como fuente de sustancias de interés. Las diferencias en composición así como las halladas en el grado de inactivación de los factores antitrípticos se explican sobre la base de los diferentes procesos que conducen a su obtención. Ambos sueros contienen carbohidratos como principales constituyentes, que es sabido que mayoritariamente son oligosacáridos con propiedades beneficiosas para el funcionamiento intestinal (Tomosatsu, 1994, Espinosa-Martos y Rupérez, 2006). Las proteínas pueden ser aisladas por precipitación con acetona, con vistas a obtener productos con actividad biológica o funcional. Lo cual convierte a los sueros en una fuente de obtención de factores antitrípticos y lectina, si estos están activos en el suero. Las diferencias en los rendimientos en la recuperación de proteínas, las determinaciones de conductividad, ceniza y metales en proteínas aisladas confirman un mayor contenido de calcio ligado en las proteínas de suero de tofu. Los estudios del comportamiento térmico de las proteínas aisladas muestran la necesidad de un tratamiento térmico de inactivación en el caso del suero de soja si este quiere ser empleado en alimentación humana o animal. La actividad residual en suero de tofu se corresponde con el estado aun nativo del factor BBTI; para su inactivación total se requerirían condiciones de calentamiento muy drásticas. Sin embargo, los ya mencionados efectos beneficiosos para la salud que puede ejercer el BBTI (Kennedy, 1993; Harms-Ringdahl et al., 1979) plantean la posibilidad de uso del suero de tofu sin una inactivación adicional.

\section{AGRADECIMIENTOS}

Al Consejo Nacional de Investigaciones Científicas y Técnicas (CONICET) y a la Agencia Nacional de Promoción Científica y Tecnológica (AMPCyT) por los subsidios PICT 2002-09-10768 y PICTOUNQ 2006-36473 y en forma especial, el apoyo financiero de la Universidad Nacional de La Plata y la Universidad Nacional de Quilmes.

\section{REFERENCIAS}

Ben Ounis, W., C.P. Champagne, J. Makhlouf y L. Bazinet; Utilization of tofu Whey pre-treated by electromembrane process as a growth medium for Lactobacillus plantarum LB17, Desalination: 229, 192-203 (2008)

Birk, Y.; Proteinase inhibitors. In Hydrolytic Enzymes Elsevier Science Publishers, pp. 257-300, A. Neuroberger \& K. Brocklehurst,. Amsterdam, Holland (1987)

Cheftel, J-C., J.L. Cuq y D. Lorient; Las proteínas de soja, en Proteínas Alimentarias, Editorial Acribia S.A., pp. 257-275, Zaragoza, España (1989)

Dubois, M. y otros cuatro autores; Colorimetric Method for Determination of Sugars, Agric. Research Service: 28 (3), 350-356 (1956)

Espinosa-Martos, I., G. Préstamo y P. Rupérez; Composición y Propiedades del Suero de Soja, un subproducto de la elaboración del tofu, Alimentaria, marzo, 72-73 (2006)

Espinosa-Martos, I. y P. Rúperez; Soybean oligosaccharides. Potential as new ingredients in functional food, Nutr. Hosp. 21 (1), 92-96 (2006)

González, R. y D. Carrillo; Nutrición humana. Manual de prácticas, pp. 34-36, Ed. Pueblo y Educación, La Habana, Cuba (1987)

Harms-Ringdahl, M., J. Forsberg, I. Fedorcsák y L. Ehrenberg; Trypsin inhibitory activity of a polypeptide isolated from red kidney beans that also enhances lymphocyte stimulation. Biochem. Biophys. Res. Commun.: 86, 492-499 (1979) 
Kennedy, A.R.; Anticarcinogenic activity of protease inhibitors. In Protease Inhibitors as Cancer Chemopreventive Agents. Edited by Troll, W. \& Kennedy, A. R., pp. 9-64, Plenum Press, New York, USA (1993)

Koshiyama, Y., Kikuchi, M. y D. Fucushima; 2S Globulins of soybean seeds. 2. Physicochemical and biological properties of protease inhibitors in $2 S$ globulins. J. Agric. Food Chem.: 29(2), 340-343 (1981)

Lin, P. y T.B. Ng; Stable Trypsin inhibitor from Chinese dull black soybeans with potentially exploitable activities. Proc. Biochem.: 43, 993-998 (2008)

Liu, K.S.; Soybeans chemistry, technology and utilization. Gaithersburg, Maryland: Aspen Publishers (1999).

Lowry, O.H.; N.J. Rosembroug, A.L. Farr y R.J. Randall; Protein measurement with the Folin Phenol reagent. J. Biol. Chem.: 193, 265-275 (1951)

Pearson, A.M.; Soy proteins. In Developments in Food Protein-2 (edición) (B.J.F. Hudson, ed), pp. 67-108. Applied Science. Pub., Londres, Ingalterra (1983)

Scilingo, A.A. y M.C. Añón; Calorimetric study of soybean proein isolates: effect of calcium and thermal treatment. J. Agric. Food Chem.: 44 (12), 3751-3756 (1996).

Sobral, P.A. y J.R. Wagner; Thermal properties of soybean whey and its protein. In Functional Properties of Food Components, pp. 57-76, Lupano, C.E. (Ed). Research Signpost, Kerala, India (2007).

Sorgentini, D.A. y J.R. Wagner ; Comparative study of structural characteristics and thermal behavior of whey and isolate soybean proteins, J. Food Biochem.: 23(5), 489-507 (1999)

Tomosatsu, H.; Health effects of Oligosaccharides. Food Technology, October, 61-65 (1994)

USDA, National Nutrient Database for Standard Reference, Release 17 (2004) Departamento de Agricultura de los Estados Unidos (USDA) Base Nacional de Datos, sobre, nutrientes como estándar de referencia, $17^{a}$ Edición (2004). http://www.nal.usda.gov/fnic/foodcomp. Acceso: 11 de noviembre de 2008

Valentas, K.J., L. Levine y J.P. Clark; Soy complex, In Food Processing Operations and Scale-Up, . pp. 92 137, New York, Marcel Dekker, Inc. (1991) 
